\title{
Reduced-Order Sliding Mode Observer-based Speed Sensorless Vector Control of Double Stator Induction Motor
}

\section{Houari Khouidmi}

Hassiba Benbouali University Faculty of Technology

Po.Box 151, Hay Es-Salem Chlef 02000, Algeria, h.khouidmi@univ-chlef.dz

\begin{abstract}
Ahmed Massoum
Djillali Liabès University of Sidi Bel-abbès, Faculty of Technology

Sidi Bel-abbès, 22000 Algeria, amassoum@univ-sba.dz
\end{abstract}

Abstract: In this paper a reduced-order sliding mode observer-based speed sensorless vector control of a double stator induction motor (DSIM) is presented. The conventional reduced-order observer has large chattering on the speed and the torque. In order to solve this problem, the sliding mode technique with smooth function is used. The simulation tests show the effectiveness of the proposed method especially in the load disturbances and/or the change of the reference speed.

Keywords: Double stator induction motor; Indirect Field Oriented Control; Reduced-order observer; Sliding mode observer; Sensorless control

\section{Introduction}

Sensorless speed vector control is a currently a fundamental part of industrial reseach because it features in the strategic business plans of most manufacturers of electric actuators [1-2]. Indeed, the operation with mechanical speed sensorless vector control has become one of the main interests of researchers currently trying to fulfill its function implicitly by electrical sensors and algorithms to reconstruct the motor speed.

The field oriented control (FOC), developed for double stator induction machine (DSIM), requires the measurement of the speed to perform the coordinate transformations. Physically, this measurement is performed using a mechanical speed sensor mounted on the rotor shaft, which unfortunately increases the 
complexity and cost of installation (additional wiring and maintenance) [3-5]. Moreover, the mechanical speed sensors are usually expensive, fragile and affect the reliability of the control. In this context, our study focuses mainly the speed estimation using the Luenberger reduced-order observer for a sensorless vector control of a double stator induction motor.

The observers are very attractive and give good performance in a wide range of speeds. The observation algorithms are using an analytical model of the machine to produce the speed and the rotor flux estimations from the stators' currents and voltages.

Among the observational methods we have deterministic observers (Luenberger, reduced order or full order observer), the Kalman filter, and the Model Reference Adaptive System (MRAS). These observers are used to observe the flux and speed estimation in a closed loop [4] [6-7]. Although such approaches lead to different performance in relation to the degree of algorithmic and computational complexity, they generally offer good performance in a wide range of speed but cannot estimate very low speeds in a stable manner [8-9].

The sliding mode observer represents one of the most attractive and popular solutions for sensorless control of electrical motor drives. Currently, applications of this strategy to double stator induction motors (DSIM) are largely unexplored and involve only a few research laboratories. For example reduced-order observer has been applied to IMs for speed sensorless control [10-11], for speed and flux sensorless control [12] and, later, for speed and/or flux sensorless control of DSIM [13-14]. However, some limitations on operation of conventional observers were large chattering on the speed, which very low speeds quickly highlighted.[8-9].

The chattering phenomenon is harmful to the proper functioning of the system, because it adds high frequency components to the control signal spectrum. These components can damage the system by exciting the dynamics neglected in the modelling or by damaging the actuators from frequent solicitations.

The main contribution of this paper is to overcome this inconvenience in DSIM observation. Many studies have been performed [15-16]. One of them involved replacing the "sign" function by a continuous approximation near the sliding surface. Among the methods which reduce the effect of the "sign" function, we find the "smooth" function of dead zone suitable for filtering high frequencies and eliminating the chattering phenomenon and generated transient electromagnetic torque in dynamic and low speed profiles.

The paper is organized as follows: the reduced-order observer structure is discussed in Section 2. In Section 3, the double stator induction motor (DSIM) model and the control strategy are presented. In Section 4 the reduced-order observer of DSIM is developed. Sections 5 and 6 provides the application of the resulting sliding mode speed observer of DSIM. Finally, a numerical simulation and its discussion are presented regarding the sensorless indirect vector control scheme of DSIM with reduced-order sliding mode speed observer shown in Fig. 1. 


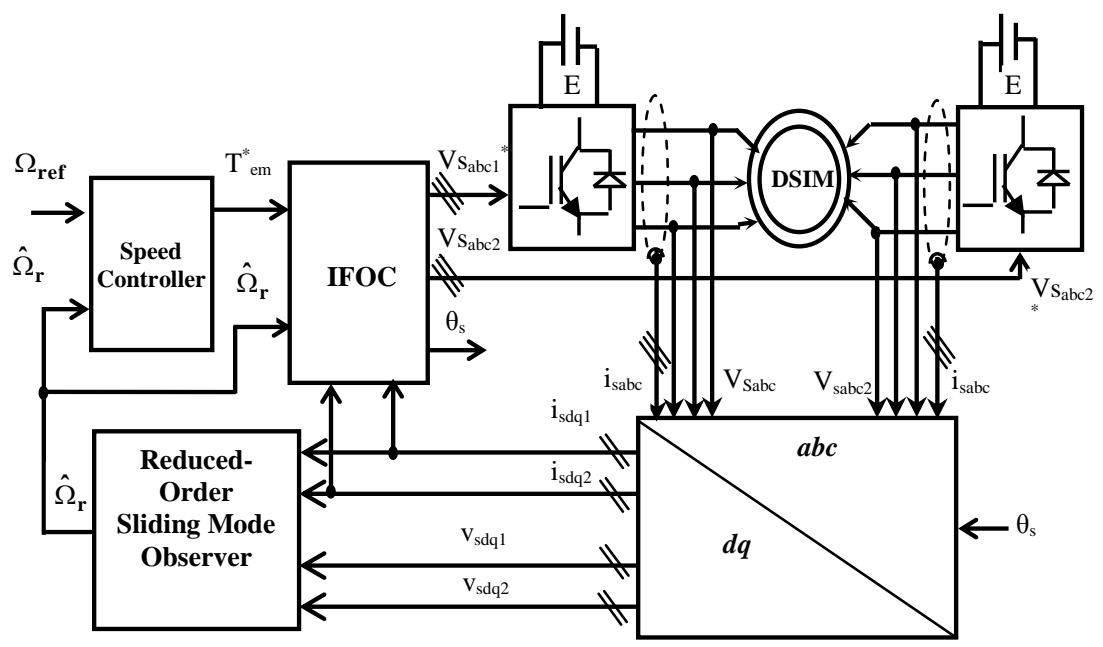

Figure 1

Sensorless indirect vector control of DSIM

\section{DSIM Model and Rotor Flux Orientation Technique}

\subsection{DSIM Model}

The double stator induction motor (DSIM) has two systems of three-phase winding (a1, b1, c1) and (a2, b2, c2) connected in a star configuration which are phase-shifted by $30^{\circ}$ (Figure 2). The equations of this machine can be expressed in different reference field (rotating field, stator field or rotor field) according to the attributed reference $(d, q)$.
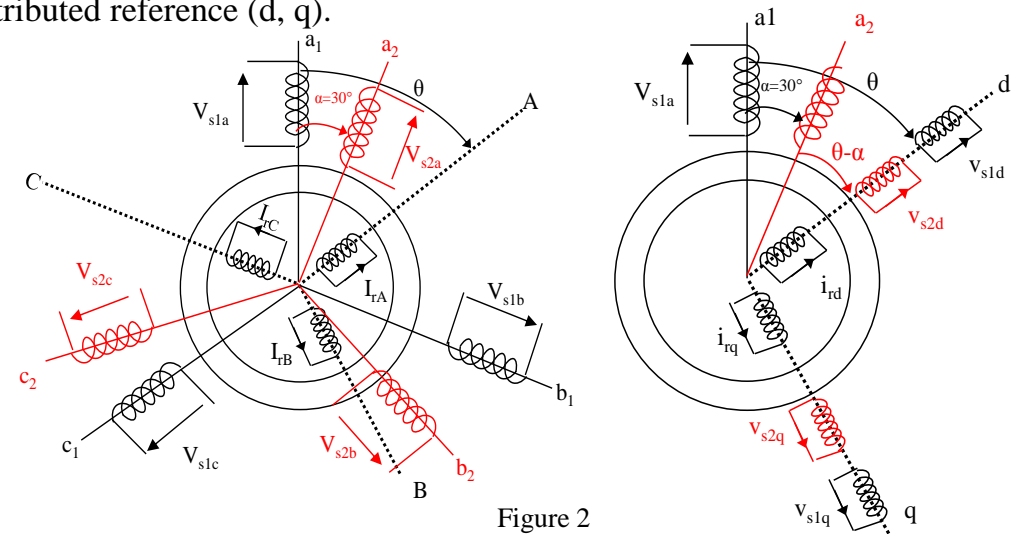

Six dimensional and orthogonal subspaces d-q model of DSIM 


\section{Voltages Equations}

By choosing a referential related to the rotating field, we obtain the following system of equations[3]-[13]:

$$
\left\{\begin{array}{l}
v_{s d 1}=R_{s 1} i_{s d 1}+\frac{d \Phi_{s d 1}}{d t}-\omega_{s} \Phi_{s q 1} \\
v_{s q 1}=R_{s 1} i_{s q 1}+\frac{d \Phi_{s q 1}}{d t}-\omega_{s} \Phi_{s d 1} \\
v_{s d 2}=R_{s 2} i_{s d 2}+\frac{d \Phi_{s d 2}}{d t}-\omega_{s} \Phi_{s q 2} \\
v_{s q 2}=R_{s 2} i_{s q 2}+\frac{d \Phi_{s q 2}}{d t}-\omega_{s} \Phi_{s d 2} \\
0=R_{r} i_{r d}+\frac{d \Phi_{r d}}{d t}-\left(\omega_{s}-\omega_{r}\right) \Phi_{r q} \\
0=R_{r} i_{r q}+\frac{d \Phi_{r q}}{d t}-\left(\omega_{s}-\omega_{r}\right) \Phi_{r d}
\end{array}\right.
$$

Where:

$$
\begin{array}{ll}
v_{s l d q} v_{s 2 d q} & : \text { First and second stator voltages in stationary frame } \\
i_{s l d q} i_{s 2 d q} & : \text { First and second stator currents in Stationary frame } \\
\Phi_{s l d q} \Phi_{s 2 d q} & : \text { First and second stator flux in stationary frame } \\
\Phi_{r d q} & : \text { Rotor flux in stationary frame } \\
\omega_{r}, \omega_{s} \omega_{g} & : \text { :Rotor and stator angular frequency } \\
R_{s 12} R_{r} & : \text { :First and second stator and rotor resistance }
\end{array}
$$

\section{Flux Equations}

The relations between flux and currents are given by:

$$
\left\{\begin{array}{l}
\Phi_{s d 1}=L_{s 1} i_{s d 1}+L_{m}\left(i_{s d 1}+i_{s d 2}+i_{r d}\right) \\
\Phi_{s q 1}=L_{s 1} i_{s q 1}+L_{m}\left(i_{s q 1}+i_{s q 2}+i_{r q}\right) \\
\Phi_{s d 2}=L_{s 2} i_{s d 2}+L_{m}\left(i_{s d 1}+i_{s d 2}+i_{r d}\right) \\
\Phi_{s q 2}=L_{s 2} i_{s q 2}+L_{m}\left(i_{s q 1}+i_{s q 2}+i_{r q}\right) \\
\Phi_{r d}=L_{r} i_{r d}+L_{m}\left(i_{s d 1}+i_{s d 2}+i_{r d}\right) \\
\Phi_{r q}=L_{r} i_{r q}+L_{m}\left(i_{s q 1}+i_{s q 2}+i_{r q}\right)
\end{array}\right.
$$

Where:

$$
\begin{array}{ll}
L_{s 12} & : \text { First and second stator inductance } \\
L_{r} & : \text { Rotor inductance } \\
L_{m} & \text { :Mutual inductance }
\end{array}
$$

Replacing the system of equations (2) in (1) we obtain the mathematical DSIM model (3). 


$$
\begin{aligned}
& \int v_{s d 1}=R_{s 1} i_{s d 1}+\left(L_{s 1}+L_{m}\right) \sigma \frac{d i_{s d 1}}{d t}+\frac{L_{m} L_{r}}{L_{m}+L_{r}} \frac{d i_{s d 2}}{d t}+\frac{L_{m}}{L_{m}+L_{r}} \frac{d \Phi_{r d}}{d t} \\
& -\omega_{s}\left[\left(L_{s 1}+L_{m}\right) \sigma i_{s q 1}+\frac{L_{m} L_{r}}{L_{m}+L_{r}} i_{s q 2}+\frac{L_{m}}{L_{m}+L_{r}} \Phi_{r q}\right] \\
& v_{s q 1}=R_{s 1} i_{s q 1}+\left(L_{s 1}+L_{m}\right) \sigma \frac{d i_{s q 1}}{d t}+\frac{L_{m} L_{r}}{L_{m}+L_{r}} \frac{d i_{s q 2}}{d t}+\frac{L_{m}}{L_{m}+L_{r}} \frac{d \Phi_{r q}}{d t} \\
& +\omega_{s}\left[\left(L_{s 1}+L_{m}\right) \sigma i_{s d 1}+\frac{L_{m} L_{r}}{L_{m}+L_{r}} i_{s d 2}+\frac{L_{m}}{L_{m}+L_{r}} \Phi_{r d}\right] \\
& \left\{v_{s d 2}=R_{s 1} i_{s d 2}+\left(L_{s 2}+L_{m}\right) \sigma \frac{d i_{s d 2}}{d t}+\frac{L_{m} L_{r}}{L_{m}+L_{r}} \frac{d i_{s d 1}}{d t}+\frac{L_{m}}{L_{m}+L_{r}} \frac{d \Phi_{r d}}{d t}\right. \\
& -\omega_{s}\left[\left(L_{s 2}+L_{m}\right) i_{s q 2}+\frac{L_{m} L_{r}}{L_{m}+L_{r}} i_{s q 1}+\frac{L_{m}}{L_{m}+L_{r}} \Phi_{r q}\right] \\
& v_{s q 2}=R_{s 1} i_{s q 2}+\left(L_{s 2}+L_{m}\right) \sigma \frac{d i_{s q 2}}{d t}+\frac{L_{m} L_{r}}{L_{m}+L_{r}} \frac{d i_{s q 1}}{d t}+\frac{L_{m}}{L_{m}+L_{r}} \frac{d \Phi_{r q}}{d t} \\
& +\omega_{s}\left[\left(L_{s 2}+L_{m}\right) \sigma i_{s d 2}+\frac{L_{m} L_{r}}{L_{m}+L_{r}} i_{s d 1}+\frac{L_{m}}{L_{m}+L_{r}} \Phi_{r d}\right] \\
& 0=-\frac{L_{m}}{T_{r}}\left(i_{s d 1}+i_{s d 2}\right)+\frac{1}{T_{r}} \Phi_{r d}+\frac{d \Phi_{r d}}{d t}-\left(\omega_{s}-\omega_{r}\right) \Phi_{r q} \\
& 0=-\frac{L_{m}}{T_{r}}\left(i_{s q 1}+i_{s q 2}\right)+\frac{1}{T_{r}} \Phi_{r q}+\frac{d \Phi_{r q}}{d t}-\left(\omega_{s}-\omega_{r}\right) \Phi_{r d}
\end{aligned}
$$

With: $\sigma=1-\frac{L_{m}^{2}}{\left(L_{m}+L_{r}\right)\left(L_{m}+L_{s}\right)}, \quad L_{s 1}=L_{s 2}=L_{s}, T_{r}=\frac{L_{m}+L_{r}}{R_{r}}$

Where:

$$
\begin{array}{cl}
\sigma & : \text { Total leakage factor; } \\
T_{r} & \text { :Rotor time constant. }
\end{array}
$$

\section{Mechanical Equations}

The equation of the electromagnetic torque is:

$$
T_{e m}=p \frac{L_{m}}{L_{m}+L_{r}}\left[\left(i_{s q 1}+i_{s q 2}\right) \Phi_{r d}-\left(i_{s d 1}+i_{s d 2}\right) \Phi_{r q}\right]
$$

Where:

$$
\begin{array}{ll}
T_{e m} & \text { :Electromagnetique torque; } \\
p & \text { :Number of pole pairs }
\end{array}
$$

The mechanical equation is:

$$
J \frac{d \Omega_{r}}{d t}=T_{e m}-T_{L}-k_{f} \Omega_{r}
$$


Where:

$J \quad$ :Inirtia;

$\Omega_{r} \quad$ :Mechanical rotor speed

$T_{L} \quad$ :Load torque

$k_{f} \quad:$ Viscous friction coefficient

\subsection{Rotor Flux Orientation Technique of DSIM}

The rotor flux orientation principle aligns the rotor flux on the direct axis [14][16]:

$\left\{\begin{array}{l}\Phi_{r}=\Phi_{r d} \\ \Phi_{r q}=0\end{array}\right.$

By imposing the condition of the rotor flux (6) to the system of equations (3) and after rearranging the mechanical equations (4) and (5), we obtain the system (7) as follows: 


$$
\begin{aligned}
& \int v_{s d 1}=R_{s 1} i_{s d 1}+\left(L_{s 1}+L_{m}\right) \sigma \frac{d i_{s d 1}}{d t}+\frac{L_{m} L_{r}}{L_{m}+L_{r}} \frac{d i_{s d 2}}{d t}+\frac{L_{m}}{L_{m}+L_{r}} \frac{d \Phi_{r}}{d t} \\
& -\omega_{s}\left[\left(L_{s 1}+L_{m}\right) \sigma i_{s q 1}+\frac{L_{m} L_{r}}{L_{m}+L_{r}} i_{s q 2}\right] \\
& v_{s q 1}=R_{s 1} i_{s q 1}+\left(L_{s 1}+L_{m}\right) \sigma \frac{d i_{s q 1}}{d t}+\frac{L_{m} L_{r}}{L_{m}+L_{r}} \frac{d i_{s q 2}}{d t} \\
& +\omega_{s}\left[\left(L_{s 1}+L_{m}\right) \sigma i_{s d 1}+\frac{L_{m} L_{r}}{L_{m}+L_{r}} i_{s d 2}+\frac{L_{m}}{L_{m}+L_{r}} \Phi_{r}\right] \\
& v_{s d 2}=R_{s 1} i_{s d 2}+\left(L_{s 2}+L_{m}\right) \sigma \frac{d i_{s d 2}}{d t}+\frac{L_{m} L_{r}}{L_{m}+L_{r}} \frac{d i_{s d 1}}{d t}+\frac{L_{m}}{L_{m}+L_{r}} \frac{d \Phi_{r}}{d t} \\
& -\omega_{s}\left[\left(L_{s 2}+L_{m}\right) \sigma i_{s q 2}+\frac{L_{m} L_{r}}{L_{m}+L_{r}} i_{s q 1}\right] \\
& v_{s q 2}=R_{s 1} i_{s q 2}+\left(L_{s 2}+L_{m}\right) \sigma \frac{d i_{s q 2}}{d t}+\frac{L_{m} L_{r}}{L_{m}+L_{r}} \frac{d i_{s q 1}}{d t} \\
& +\omega_{s}\left[\left(L_{s 2}+L_{m}\right) \sigma i_{s d 2}+\frac{L_{m} L_{r}}{L_{m}+L_{r}} i_{s d 1}+\frac{L_{m}}{L_{m}+L_{r}} \Phi_{r}\right] \\
& 0=-\frac{L_{m}}{T_{r}}\left(i_{s d 1}+i_{s d 2}\right)+\frac{1}{T_{r}} \Phi_{r}+\frac{d \Phi_{r}}{d t} \\
& 0=-\frac{L_{m}}{T_{r}}\left(i_{s q 1}+i_{s q 2}\right)-\left(\omega_{s}-\omega_{r}\right) \Phi_{r} \\
& \left\{\begin{array}{l}
T_{e m}=p \frac{L_{m}}{L_{m}+L_{r}} \cdot \Phi_{r} \cdot\left(i_{s q 1}+i_{s q 2}\right) \\
J \frac{d \Omega_{r}}{d t}=T_{e m}-T_{L}-k_{f} \Omega_{r}
\end{array}\right.
\end{aligned}
$$

To ensure the torque control and to provide at all times the maximum torque, the flux is maintained at its nominal value. In contrast, the voltages equations $\mathrm{v}_{\mathrm{sd} 1}, \mathrm{v}_{\mathrm{sq} 1}, \mathrm{v}_{\mathrm{sd} 2}$ and $\mathrm{v}_{\mathrm{sq} 2}$ show undesired coupling, which requires the use of a decoupling circuit during the implementation of the field oriented control [11][16].

Taking into account that $\Phi_{r}$ is kept constant at its nominal value, in the established regime we have $\frac{d \Phi_{r}}{d t}=0$, and system (7) becomes (8): 


$$
\left\{\begin{array}{l}
v_{s d 1}=R_{s 1} i_{s d 1}-L_{s 1} \frac{d i_{s d 1}}{d t}-\omega_{s} \cdot L_{s 1} \cdot\left(\frac{L_{r}}{R_{r}} \Phi_{r} \cdot \omega_{g l}+L_{s 1} i_{s q 1}\right) \\
v_{s d 2}=+R_{s 2} i_{s d 2}-L_{s 2} \frac{d i_{s d 2}}{d t}-\omega_{s} \cdot L_{s 2} \cdot\left(\frac{L_{r}}{R_{r}} \Phi_{r} . \omega_{g l}+L_{s 2} i_{s q 2}\right) \\
v_{s q 1}=R_{s 1} i_{s q 1}-L_{s 1} \frac{d i_{s q 1}}{d t}+\omega_{s} L_{s 1} \cdot\left(\Phi_{r}+L_{s 1} i_{s d 1}\right) \\
v_{s q 2}=R_{s 2} i_{s q 2}-L_{s 2} \frac{d i_{s q 2}}{d t}+\omega_{s} L_{s 2} \cdot\left(\Phi_{r}+L_{s 2} i_{s d 2}\right) \\
\frac{1}{T_{r}} . \Phi_{r}+\frac{d \Phi_{r}}{d t}=\frac{L_{m}}{T_{r}}\left(i_{s d 1}+i_{s d 2}\right) \\
\omega_{g l}=\omega_{s}-\omega_{r}=\frac{L_{m}}{T_{r} \Phi_{r}}\left(i_{s q 1}+i_{s q 2}\right) \\
T_{e m}=p \frac{L_{m}}{L_{m}+L_{r}} \Phi_{r}\left(i_{s q 1}+i_{s q 2}\right) \\
J \frac{d \Omega_{r}}{d t}=T_{e m}-T_{L}-k_{f} \Omega_{r}
\end{array}\right.
$$

\section{Reduced-Order Observer}

An observer is an estimator operating in closed loop with an independent dynamic system [7]-[10]. It provides an estimate of the internal physical quantity of a system, based only on information about the input and output of the system with the feedback input of the measured outputs and the estimated error, using the gain matrix $G$ to make the error dynamics converge to zero dynamics (Figure 3).

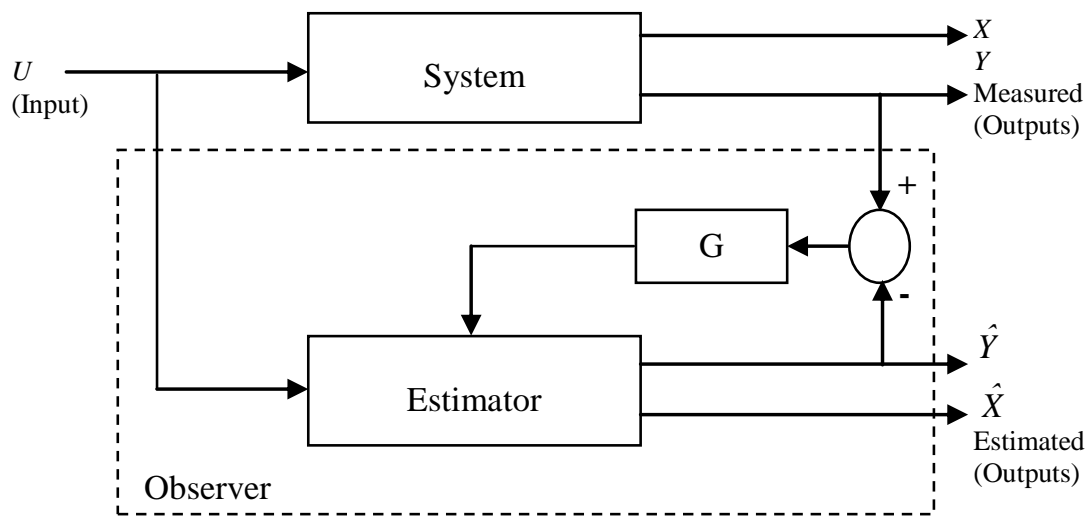

Figure 3

Overall structure of an observer 
The system shown in Figure 4 is defined by the state form as follows:

$\left\{\begin{array}{l}\frac{d X}{d t}=A(\Omega) X+B U \\ Y=C X\end{array}\right.$

Where $B$ is the input matrix of the system, $C$ is the output matrix and $A(\Omega)$ is the non-stationary transition matrix of our system, since it depends on the rotational speed. However, it can be considered as quasi-stationary for the dynamic speed with respect to that of the electrical quantities.

By integrating equation (9), we can reconstruct the estimate state.

$$
\hat{X}=\int(\hat{A}(\Omega) \hat{X}+\hat{B} \cdot U) d t
$$

To evaluate the accuracy of the estimate, we consider the difference between the measured and estimated states:

$\varepsilon=X-\hat{X}$

Then the dynamic error is deduced from relations (9) and (10):

$\frac{d \varepsilon}{d t}=A(\Omega) \varepsilon+\Delta A \hat{X}+\Delta B U$

Where:

$\Delta A=A(\Omega)-\hat{A}(\Omega)$ and $\Delta B=B-\hat{B}$

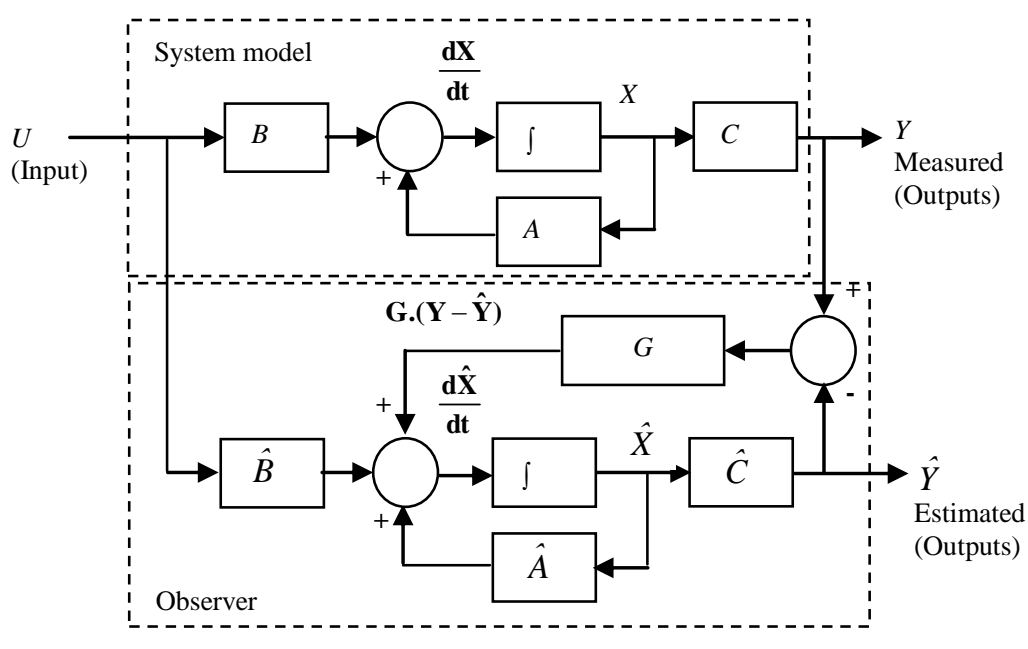

Figure 4

State space form of an observer 
The principle construction of an observer is therefore to correct the dynamic of the estimate in (10) taking into account the difference between the measured output and the estimated output. This leads to the following observer [10]:

$$
\frac{d \hat{X}}{d t}=A(\Omega) \hat{X}+B U+G C \varepsilon
$$

Where: $G$ is the gain of the observer.

We can construct a Luenberger observer by substituting equation (11) into (13) as follows:

$$
\frac{d \hat{X}}{d t}=A(\hat{\Omega}) \cdot \hat{X}+B U+G(Y-C \hat{X})
$$

The problem with this type of observer is that the selection of $G$ depends generally on the estimated speed $\hat{\Omega}$ and involves a dynamic decay of the estimation errors.

We define as measurement error the difference between the measured and estimated variables. In the same way as the estimator, the equation describing the behavior of the estimation error is obtained using equations (9) and (13). So the equation of the estimation error becomes:

$$
\frac{d \varepsilon}{d t}=(A(\Omega)-G C) \cdot \varepsilon+(\Delta A-G \Delta C) \cdot \hat{X}+\Delta B U
$$

The main advantage of the observer to the estimator can be easily shown by equation (15). Indeed, the dynamics of convergence error is controlled by the term $(A(\Omega)-G C)$ with the correction gain matrix $G$.

\section{Reduced-Order Speed Observer of DSIM}

The use of an estimator does not allow controlling the dynamics of the error that depends on the physical system. Thus, it is preferable that the dynamics of the process estimation is much faster than the system itself, hence the interest using the observers.

The mathematical model of the DSIM shows a variable nonlinear system. To overcome this nonlinearity we use a linear observer and take $\Omega_{r}$ as an additional variable. In this case, we have a Luenberger observer obtained from the system of equations (15) [10]-[12].

We can rewrite the system of equations (15) in the form of two sub-systems as follows: 


$$
\begin{aligned}
& \left\{\begin{array}{l}
\frac{d i_{s d 1}}{d t}=\frac{1}{L_{s 1}} v_{s d 1}-\frac{R_{s 1}}{L_{s 1}} i_{s d 1}+\omega_{s}\left(\frac{L_{r}}{R_{r}} \Phi_{r} . \omega_{g l}+L_{s 1} i_{s q 1}\right) \\
\frac{d i_{s d 2}}{d t}=\frac{1}{L_{s 2}} v_{s d 2}-\frac{R_{s 2}}{L_{s 2}} i_{s d 2}+\omega_{s} \cdot\left(\frac{L_{r}}{R_{r}} \Phi_{r} . \omega_{g l}+L_{s 2} i_{s q 2}\right) \\
\frac{d \Phi_{r}}{d t}=\frac{L_{m}}{T_{r}}\left(i_{s d 1}+i_{s d 2}\right)-\frac{1}{T_{r}} \Phi_{r}
\end{array}\right. \\
& \left\{\begin{array}{l}
\frac{d i_{s q 1}}{d t}=\frac{1}{L_{s 1}} v_{s q 1}-\frac{R_{s 1}}{L_{s 1}} \cdot i_{s q 1}-\omega_{s}\left(\Phi_{r}+L_{s 1} i_{s d 1}\right) \\
\frac{d i_{s q 2}}{d t}=\frac{1}{L_{s 2}} v_{s q 2}-\frac{R_{s 2}}{L_{s 2}} \cdot i_{s q 2}-\omega_{s}\left(\Phi_{r}+L_{s 2} i_{s d 2}\right) \\
\frac{d \Omega_{r}}{d t}=\frac{p}{J} \frac{L_{m}}{L_{m}+L_{r}} \Phi_{r}\left(i_{s q 1}+i_{s q 2}\right)-\frac{1}{J}\left(k_{f} \Omega_{r}+T_{L}\right)
\end{array}\right.
\end{aligned}
$$

It is clear that the estimated speed described by subsystem (17) requires the estimated load torque and the rotor flux.

We can use the following model to estimate the torque load $T_{L}[13]$ :

$$
\frac{d T_{L}}{d t} \cong 0
$$

By adding the equation (18) to the subsystems (17), we obtain:

$$
\left\{\begin{array}{l}
\frac{d i_{s q 1}}{d t}=\frac{1}{L_{s 1}} v_{s q 1}-\frac{R_{s 1}}{L_{s 1}} i_{s q 1}-\omega_{s}\left(\Phi_{r}+L_{s 1} i_{s d 1}\right) \\
\frac{d i_{s q 2}}{d t}=\frac{1}{L_{s 2}} v_{s q 2}-\frac{R_{s 2}}{L_{s 2}} i_{s q 2}-\omega_{s}\left(\Phi_{r}+L_{s 2} i_{s d 2}\right) \\
\frac{d \Omega_{r}}{d t}=\frac{p}{J} \frac{L_{m}}{L_{m}+L_{r}} \Phi_{r}\left(i_{s q 1}+i_{s q 2}\right)-\frac{1}{J}\left(k_{f} \Omega_{r}+T_{L}\right) \\
\frac{d T_{L}}{d t} \cong 0
\end{array}\right.
$$

From the system of equations (19) assuming $\Phi_{r}$ constant, we can construct our reduced-order observer as follows: 


$$
\left\{\begin{array}{l}
\frac{d \hat{i}_{s q 1}}{d t}=\frac{1}{L_{s 1}} v_{s q 1}-\frac{R_{s 1}}{L_{s 1}} \hat{i}_{s q 1}-\omega_{s}\left(\frac{1}{L_{s 1}} \hat{\Phi}_{r}+i_{s d 1}\right)+G_{1} \tilde{i}_{s q} \\
\frac{d \hat{i}_{s q 2}}{d t}=\frac{1}{L_{s 2}} v_{s q 2}-\frac{R_{s 2}}{L_{s 2}} \hat{i}_{s q 2}-\omega_{s}\left(\frac{1}{L_{s 2}} \hat{\Phi}_{r}+i_{s d 2}\right)+G_{1} \tilde{i}_{s q} \\
\frac{d \hat{\Omega}_{r}}{d t}=\frac{p}{J} \frac{L_{m}}{L_{m}+L_{r}} \hat{\Phi}_{r}\left(i_{s q 1}+i_{s q 2}\right)-\frac{1}{J}\left(k_{f} \hat{\Omega}_{r}+p \cdot \hat{T}_{L}\right)+G_{2} \tilde{i}_{s q} \\
\frac{d \hat{T}_{L}}{d t}=G_{3} \tilde{i}_{s q} \\
\frac{d \hat{\Phi}_{r}}{d t}=\frac{L_{m}}{T_{r}}\left(i_{s d 1}+i_{s d 2}\right)-\frac{1}{T_{r}} \hat{\Phi}_{r}
\end{array}\right.
$$

With: $\tilde{i}_{s q}=\left(i_{s q 1}+i_{s q 2}\right)-\left(\hat{i}_{s q 1}+\hat{i}_{s q 2}\right)$

$G_{1}, G_{2}$ and $G_{3}$ are the observer gains.

It is sufficient to ensure the system stability, with a specific choice of $G_{1}, G_{2}$ and $G_{3}$ dependint on the mechanical speed.

\section{Sliding Mode Speed Observer of DSIM}

To achieve good performance, the sliding mode technique is known for its robustness with respect to the parametric uncertainties through the use of High Gain [16-18]. This technique reduces the state trajectory $\frac{d \hat{X}}{d t}$ of a given system to the sliding surface $S=Y-\hat{Y} \cong \tilde{i}_{s q}$ and choses to switch the desired operating point [19].

The vector surface $S=0$ is attractive as it satisfies the Lyapunov stability criteria if $S . \dot{S}<0[20]$.

The smooth function figure (5), is used to eliminate the chattering phenomenon.

$$
\operatorname{Smooth}(S)=\frac{S}{|S|+e}
$$

Where: $e$ is a small positive parameter.

Finally, we define the sliding mode observer by adding the smooth function (21) in the system (20): 


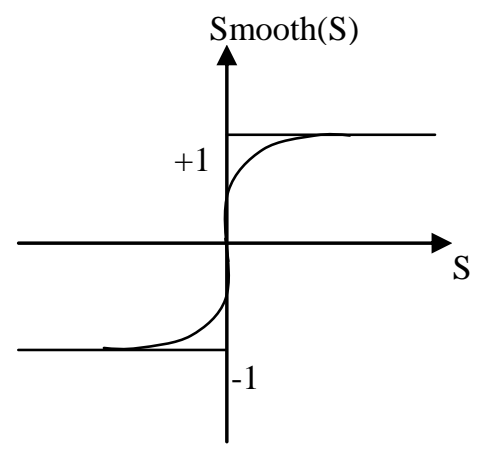

Figure 5

The Smooth function

$$
\left\{\begin{array}{l}
\frac{d \hat{i}_{s q 1}}{d t}=\frac{1}{L_{s 1}} v_{s q 1}-\frac{R_{s 1}}{L_{s 1}} \hat{i}_{s q 1}-\omega_{s}\left(\frac{1}{L_{s 1}} \hat{\Phi}_{r}+i_{s d 1}\right)+G_{1} \operatorname{Smooth}\left(\tilde{i}_{s q}\right) \\
\frac{d \hat{i}_{s q 2}}{d t}=\frac{1}{L_{s 2}} v_{s q 2}-\frac{R_{s 2}}{L_{s 2}} \hat{i}_{s q 2}-\omega_{s}\left(\frac{1}{L_{s 2}} \hat{\Phi}_{r}+i_{s d 2}\right)+G_{1} \operatorname{Smooth}\left(\tilde{i}_{s q}\right) \\
\frac{d \hat{\Omega}_{r}}{d t}=\frac{p}{J} \frac{L_{m}}{L_{m}+L_{r}} \hat{\Phi}_{r}\left(i_{s q 1}+i_{s q 2}\right)-\frac{1}{J}\left(k_{f} \hat{\Omega}_{r}+p \hat{T}_{L}\right)+G_{2} \operatorname{Smooth}\left(\tilde{i}_{s q}\right) \\
\frac{d \hat{T}_{L}}{d t}=G_{3} \operatorname{Smooth}\left(\tilde{i}_{s q}\right) \\
\frac{d \hat{\Phi}_{r}}{d t}=\frac{L_{m}}{T_{r}}\left(i_{s d 1}+i_{s d 2}\right)-\frac{1}{T_{r}} \hat{\Phi}_{r} \\
\tilde{i}_{s q}=\left(i_{s q 1}+i_{s q 2}\right)-\left(\hat{i}_{s q 1}+\hat{i}_{s q 2}\right) \\
\operatorname{Smooth}\left(\tilde{i}_{s q}\right)=\frac{\tilde{i}_{s q}}{\left|\tilde{i}_{s q}\right|+e}
\end{array}\right.
$$

\section{Simulation Results}

To test the static and the dynamic performance of the reduced-order sliding mode speed observer, the double stator induction motor (Appendix) is fed by two threelevel voltage inverters controlled by rotor flux orientation. 


\subsection{Discussion}

Figures (6-7 and 8-9) illustrate the dynamic performances of the sensorless drive at acceleration and deceleration for both high speeds $\left(\Omega_{r}=280(\mathrm{rad} / \mathrm{s}), \Omega_{r}=-280\right.$ $(\mathrm{rad} / \mathrm{s}))$ and low speeds $\left(\Omega_{r}=20(\mathrm{rad} / \mathrm{s}), \Omega_{r}=-20(\mathrm{rad} / \mathrm{s})\right)$ with step load change applied at $\mathrm{t}=1.5 \mathrm{sec}$ to $\mathrm{t}=2.5 \mathrm{sec}$ for $T_{L}=14$ (N.m) to $T_{L}=0$ (N.m).

The obtained simulation results (Figures 6 and 8, for both high and low speed ) show that the speed tends to its reference and takes its steady state after $1 \mathrm{sec}$ without overshoot. Also the direct component of rotor flux is set to $\approx 1 \mathrm{~Wb}$ after 1 sec to start, and the quadratic component is cancelled at the same time (Figures 7 and 9). During start-up, the electromagnetic torque is set to $50 \mathrm{Nm}$ and decreased to zero after $1 \mathrm{sec}$. At time $1.5 \mathrm{sec}$, a nominal load torque of $14 \mathrm{Nm}$ is applied, there was a slight decrease in speed and an increase of the stator currents. This affects the electromagnetic torque increases $(14 \mathrm{Nm})$, in order to compensate for (approximately 0.1 seconds) the load torque. We also note that the electromagnetic torque is proportional to the quadratic component of stator current; however, the flux remains constant.

It can be seen that the observed speed tracks the real one, the dynamic error is not important (Figures 8 and 9) and the static error is practically zero for both high and low speed. Generally, the reduced-order sliding mode speed observer works very well especially if the observer gains are smoothed out by the smooth function.

\subsection{Robustness Test}

In this section, the influences of parameter variations are investigated in order to test the sensitivity of our SM-observer. The sensitivity of stators resistances, rotor resistance and inertia variation is studied for a step change of $+50 \% R_{s},+50 \% R_{r}$ and $+100 \% \mathrm{~J}$ simultaneously for $\mathrm{t}=1.5 \mathrm{~s}$ to $2.5 \mathrm{~s}$ for both high and low speeds. Figures (10a) and (10b) shows that the behavior of the observer is not affected at high speeds but the speed error is highlighted at low speeds, the simulations clearly show the performance of the proposed sliding mode speed observer. 

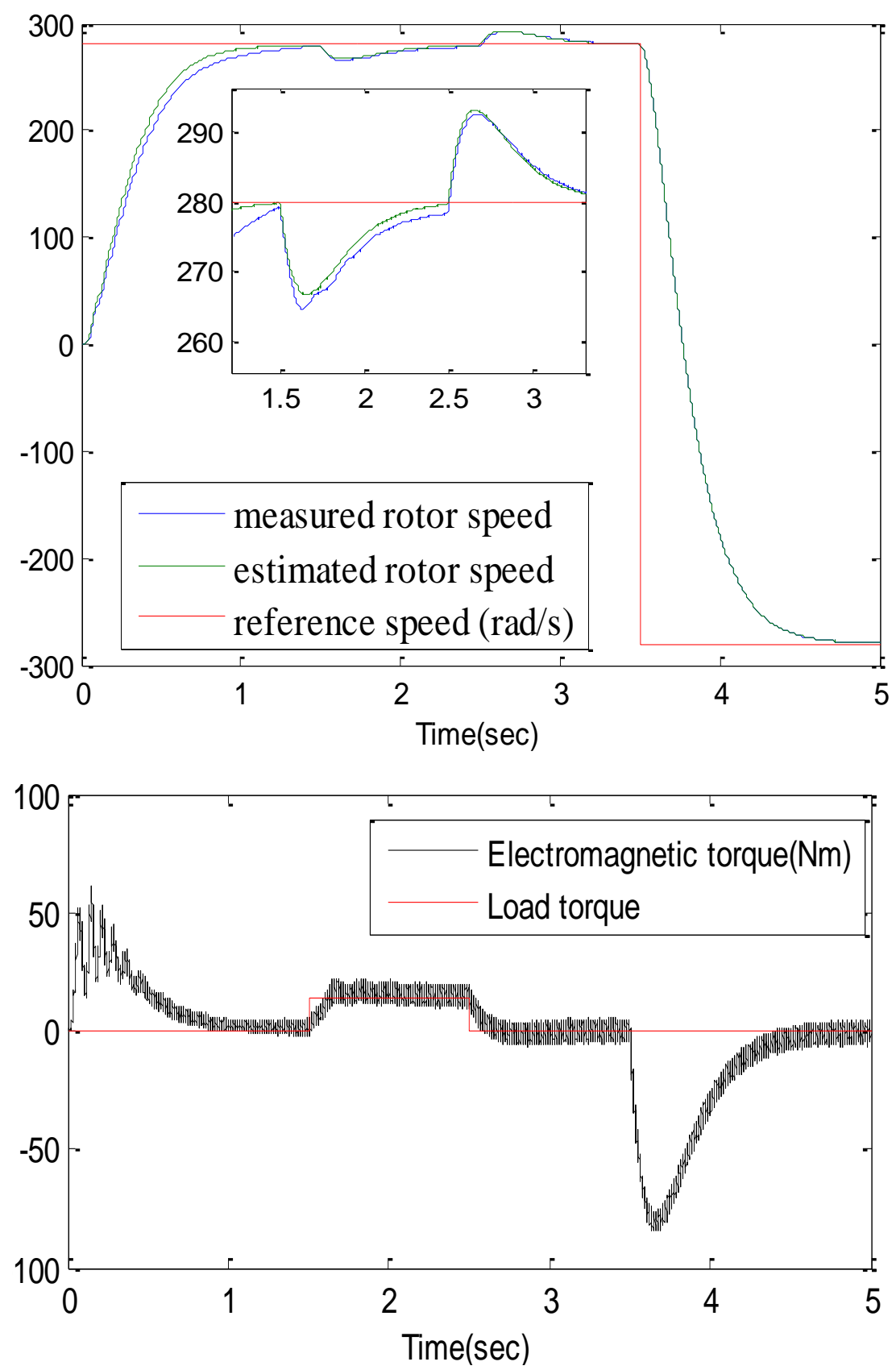

Figure 6

Measured,estimated speed and electrpmagnetic torque results for high speed sensorless control 

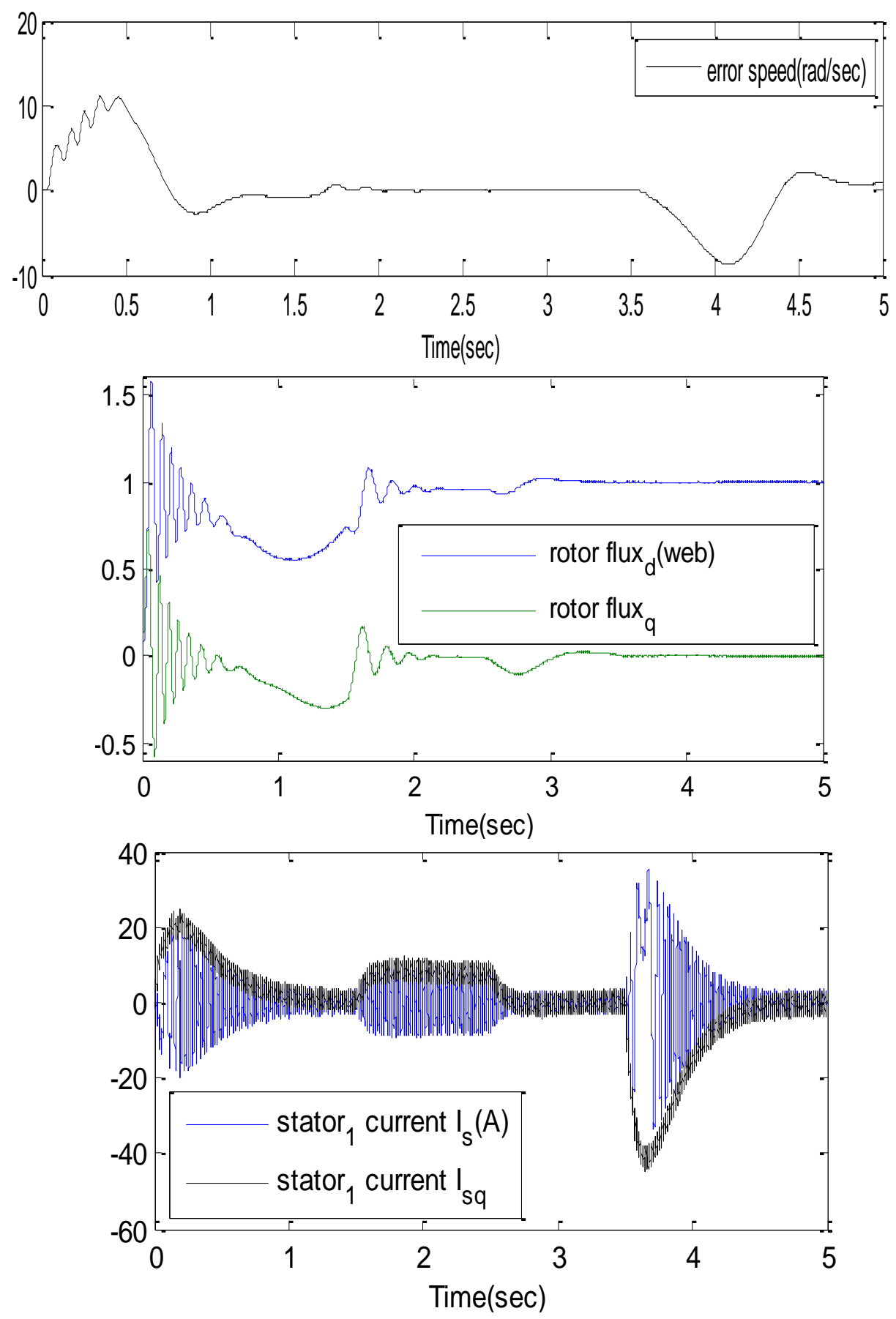

Figure 7

Error speed ,rotor flux and stator current results for high speed sensorless control 

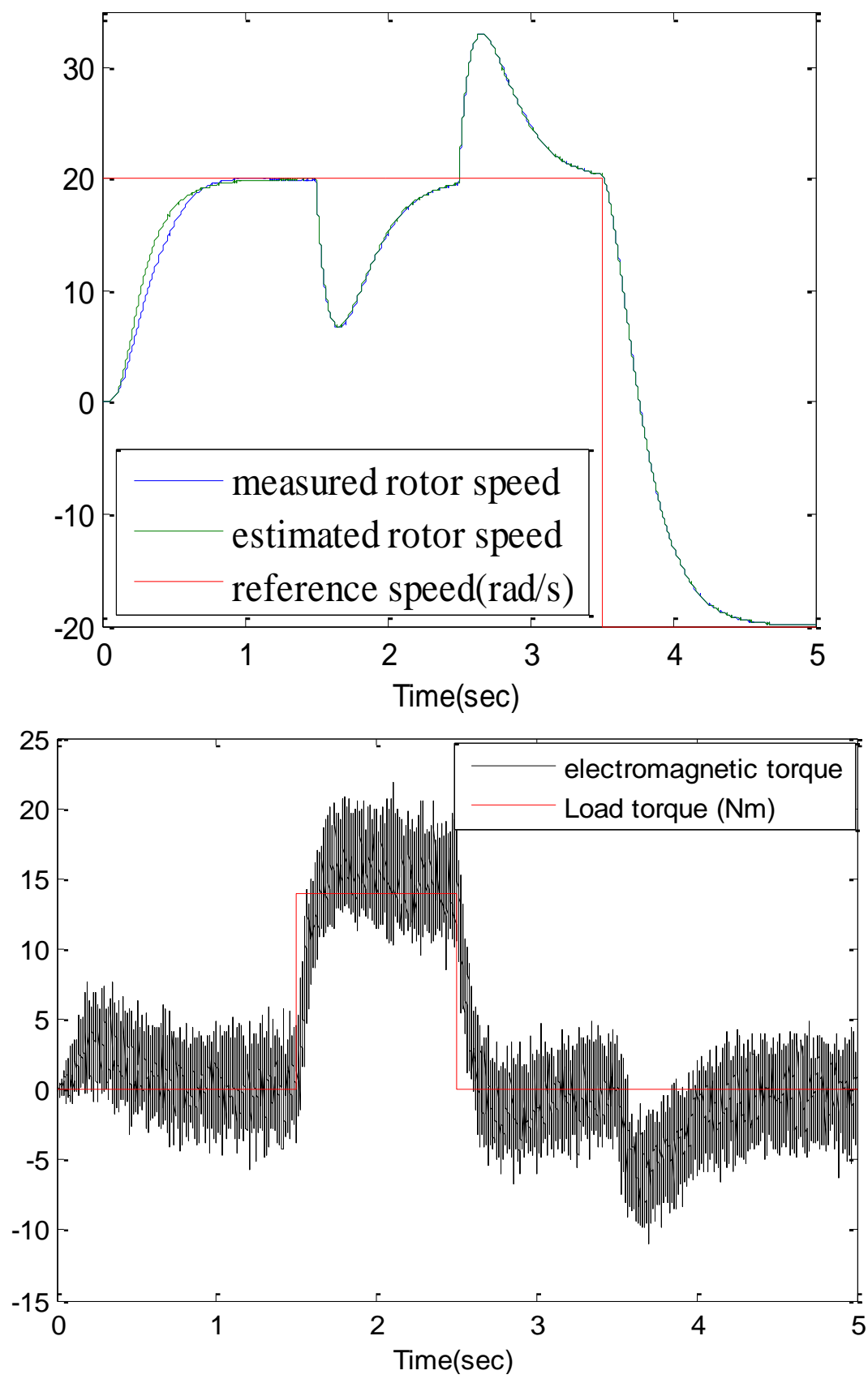

Figure 8

Measured, estimated speed and electrpmagnetic torque results for low speed sensorless control 

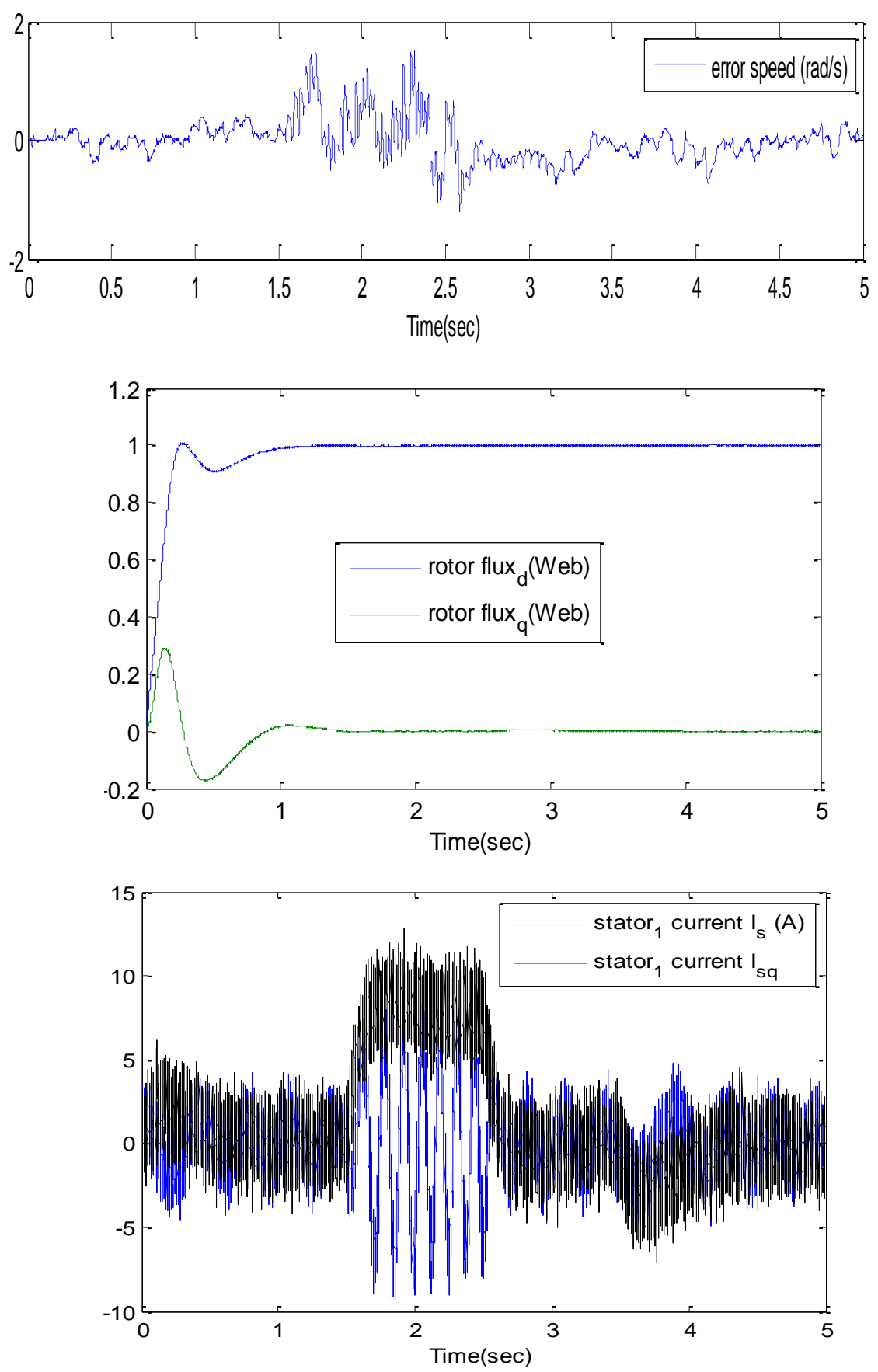

Figure 9

Error speed ,rotor flux and stator current results for low speed sensorless control 

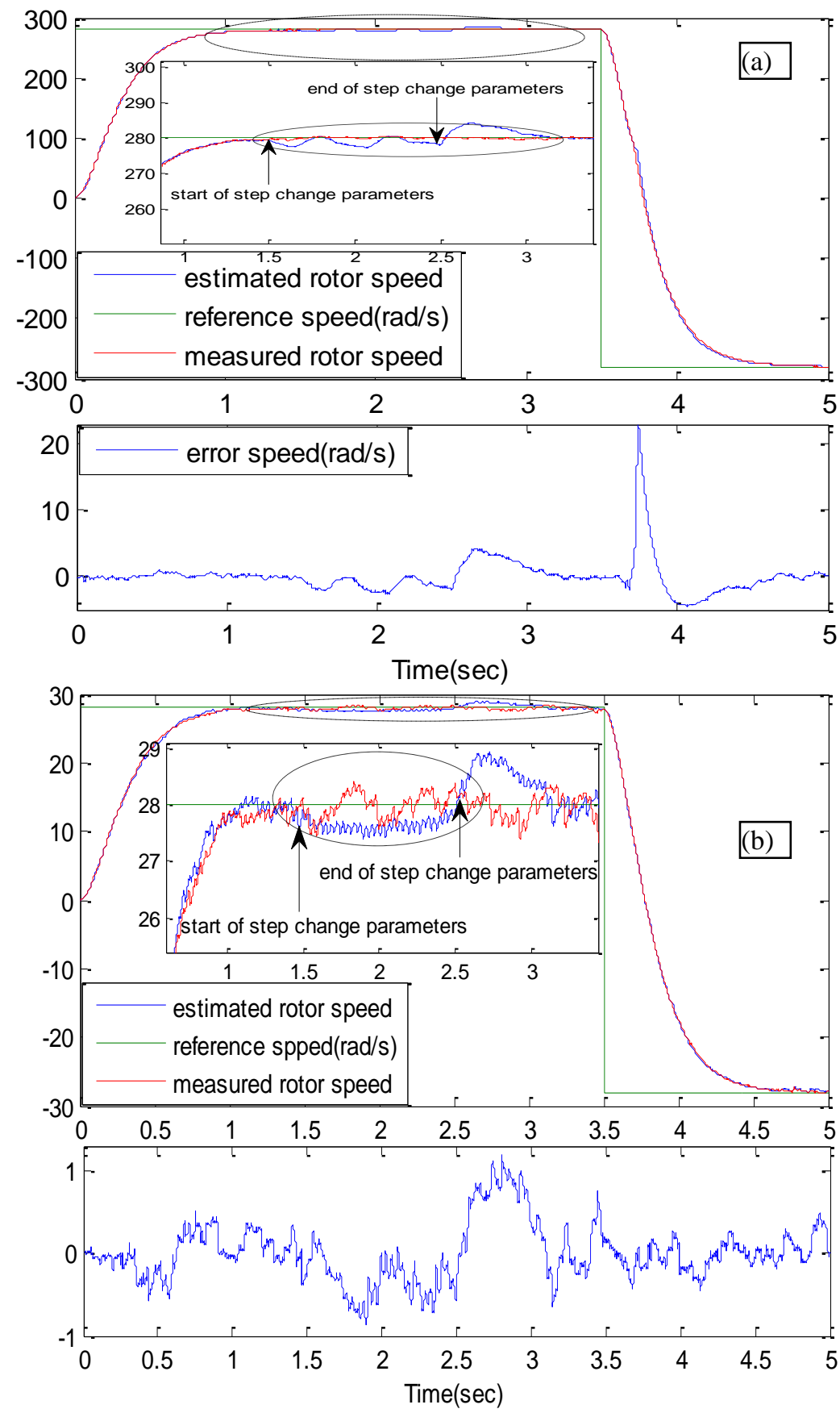

Figure 10

Robustness test; .(a) for high speed (b) for low speed sensorless vector control of DSIM 


\section{Conclusions}

In this paper we presented the sensorless vector control of DSIM, were the "sign" function used by the majority of authors is replaced with the smooth function. With the use of the "sign" function, undesired oscillations appear in the speed and torque. These oscillations can excite the neglected errors dynamics, or even damage the observer.

The sliding mode speed observer is sufficiently fast and robust with respect to parametric variation, load disturbance and the change of the reference speed. We also note that this technique is characterized by its simplicity of design and robustness; most importantly it eliminated the need for the mechanical speed sensor, which is expensive and fragile.

\section{Appendix}

Double stator induction motor parameters

$P_{n}=4.5 \mathrm{~kW}, f=50 \mathrm{~Hz}, V_{n(\Delta / \mathrm{Y})}=220 / 380 \mathrm{~V}, I_{n\left(\Delta_{/ \mathrm{Y}}\right)}=6.5 \mathrm{~A}, \Omega_{n}=2751 \mathrm{rpm}, p=1$

$R_{s l}=R_{s 2}=3.72 \Omega, R_{r}=2.12 \Omega, L_{s l}=L_{s 2}=0.022 \mathrm{H}, L_{r}=0.006 \mathrm{H}, L_{m}=0.3672 \mathrm{H}$

$J=0.0625 \mathrm{Kgm}^{2}, K_{f}=0.001 \mathrm{Nm}(\mathrm{rad} / \mathrm{s})^{-1}$

\section{References}

[1] A. Khedher, MF. Mimouni, N. Derbel, A. Masmoudi. Sensorless-Adaptive DTC of Double Star Induction Motor. Energy Convers Manage, 2010; 51: 2878-2892

[2] M. Rizwan Khan, I. Atif, A. Mukhtar. MRAS-based Sensorless Control of a Vector-controlled Five-Phase Induction Motor drive. Electric Power Systems Research, Vol. 78, 2008, pp. 1311-1321

[3] H. Ben Azza, M. Jemli, M. Boussak, M. Gossa. High Performance Sensorless Speed Vector Control of SPIM Drives with On-Line Stator Resistance Estimation. Simulation Modelling Practice and Theory, Vol. 19, 2011, pp. 271-282

[4] P. Vas. Sensorless Vector and Direct Torque Control, Oxford University Press, Oxford, 1998

[5] A. M. Trzynadlowski. Control of Induction Motors, Academic Press, London, 2001

[6] O. Aydogmus, S. Sünter. Implementation of EKF-based Sensorless Drive System using Vector-controlled PMSM Fed by a Matrix Converter. Electrical Power and Energy Systems, Vol. 43, 2012, pp. 736-743

[7] R. Nilsen, M. P. Kazmierkowski. Reduced-Order Observer with Parameter Adaptation for Fast Rotor Flux Estimation in Induction Machine. IEE Proceedings, Vol. 136, No. 1, 1989, pp. 35-43

[8] R. Beguenane, M. A. Ouhrouche, A. M. Trzynadlowski. A New Scheme for Sensorless Induction Motor Control Drives Operating in Low Speed 
Region, Mathematics and Computers in Simulation. Vol. 71, No. 02, 2006, pp. $109-120$

[9] M. S. Zaky, M. Khater, H. Yasin, S. S. Shokralla. Very Low Speed and Zero Speed Estimations of Sensorless Induction Motor Drives. Electric Power Systems Research, Vol. 80 (2010) pp. 143-151

[10] J. Song, K. B. Lee, J. H. Song, I. Choy, K. B. Kim, Sensorless Vector Control of Induction Motor using a Novel Reduced-Order Extended Luenberger Observer, Proceeding of the IEEE Industry Applications Conference, Vol. 3, 2000, pp. 1828-1834

[11] M. Menaa, O. Touhami, R. Ibtiouen, M. Fadel. Sensorless Direct Vector Control of an Induction Motor. Control Engineering Practice, Vol. 16, 2008, pp. 67-77

[12] T. S. Kwon, M. H. Shin, D. S. Hyun. Speed Sensorless Stator Flux-oriented Control of Induction Motor in the Field Weakening Region using Luenberger Observer. IEEE Trans. on Power Electron, Vol. 20, No. 04, 2005, pp. 864-869

[13] MF. Mimouni, R. Dhifaoui. A Robust Air-Gap Flux Estimation for Speed Sensorless Vector Control of Double-Star Induction Machine. Int J Adapt Control Signal Process, Vol. 18, 2004, pp. 523-46

[14] R. Kianinezhad, B. Nahid-Mobarakeh, F. Betin, G. A. Capolino. Sensorless Field-oriented Control for Six-Phase Induction Machines. IEEE Trans. on Ind. Appl, Vol. 71, 2005, pp. 999-1006

[15] A. Mezouar, M. K. Fellah, S. Hadjeri. Adaptive Sliding-Mode-Observer for Sensorless Induction Motor Drive using Two-Time-Scale Approach. Simulation Modelling Practice and Theory, Vol. 16, 2008, pp. 1323-133

[16] M. Marcello, P. Sergei, T. Andrea. A speed-Sensorless Indirect Fieldoriented Control for Induction Motors Based on High Gain Speed Estimation. Automatica, Vol. 42, 2006, pp. 1637-1650

[17] K. Vrdoljak, N. Peri'c, I. Petrovi'c. Sliding Mode-based Load-Frequency Control in Power Systems. Electric Power Systems Research, Vol. 80, 2010, pp. 514-527

[18] F. Plestan, et al. Sliding Mode Control with Gain Adaptation-Application to an Electropneumatic Actuator. Control Engineering Practice (2012) http://dx.doi.org/10.1016/j.conengprac.2012.04.012

[19] V. Brégeault, F. Plestan, Y. Shtessel, Y. Hu. Adaptive Sliding Mode Control for an Electropneumatic Actuator. In Proceedings of the international workshop on variable structure systems VSS10, 2010, Mexico, D.F., Mexico

[20] L. Jingchuan, X. Longya, Z. Zheng, An Adaptive Sliding-Mode Observer for Induction Motor Sensorless Speed Control, IEEE Transaction on Industry Applications, Vol. 41, No. 4, 2005, pp. 1039-1046 